\title{
Effects of environmental change, fisheries and trophodynamics on the ecosystem of the western Scotian Shelf, Canada
}

\author{
Júlio Neves Araújo*, Alida Bundy \\ Bedford Institute of Oceanography, Dartmouth, Nova Scotia, Canada
}

\begin{abstract}
The dynamics of marine ecosystems, which are complex and non-linear, are difficult to predict. Like most marine ecosystems, NW Atlantic systems have been subjected to centuries of fisheries exploitation as well as environmental and internal trophodynamic drivers. By reducing the complexity of the western Scotian Shelf ecosystem to 57 functional living groups, we were able to reproduce many of its observed dynamics, such as major decadal trends in abundance and mortality for most groups, and explore the relative strength within the triad of drivers using a trophodynamic model. We explored potential biophysical drivers through the use of a primary production anomaly, generated by a model fitting routine. The estimated primary production series was negatively correlated with the spring sea surface temperature for the Scotian Shelf Large Marine Ecosystem, a stratification index and the Atlantic Multidecadal Oscillation (AMO) index. The aggregated biomass of the main resident fish species was also negatively correlated with the AMO index. All 3 drivers contribute to shaping the observed biological and ecological changes of the western Scotian Shelf. This has substantial implications for fisheries management: (1) climate change (global warming) may negatively affect productivity at the species and ecosystem level ${ }_{i}(2)$ these effects may be magnified due to the combined effects of trophic interactions and exploitation; and (3) fisheries assessments must account for environmental and climate change, and for the broader ecosystem effects. Failing this, fisheries should be managed well below their single-species reference points.
\end{abstract}

KEY WORDS: Ecosystem based management · Predation mortality · Groundfish-seal interactions · Carrying capacity $\cdot$ Climate change

\section{INTRODUCTION}

Empirical analyses of ecosystem data have increased our understanding of their dynamics, leading to a more holistic view of ecosystem functioning and the potential for concrete contributions to ecosystem based management (e.g. Jennings et al. 1999, Worm \& Myers 2003, Frank et al. 2005, 2006, Benoît \& Swain 2008, Shackell et al. 2010, 2012, Shin et al. 2010). However, without an accompanying demonstration of the mechanisms behind these observations, they remain statistical descriptions of possible relationships which may continue into the future.
The necessary complementary step is to develop models to explore these statistical relationships further and explore whether the developed theory 'holds water' when it is directly modelled and the mechanisms are explored.

Marine ecosystems are complex, non-linear systems that are subject to a triad of drivers: biophysical, exploitative and trophodynamic, which summarize key themes of research that explore variation in ecosystem productivity (Link et al. 2010). Several North Atlantic ecosystems have already received considerable attention, from both empirical and modelling perspectives, such as the North Sea (Beaugrand et al. 
2003, Mackinson et al. 2009a), the Baltic Sea (Harvey et al. 2003, Ojaveer \& Eero 2011), the western English Channel (Genner et al. 2004, Southward et al. 2005, Araújo et al. 2006), the eastern Scotian Shelf (Choi et al. 2004, Frank et al. 2005, 2006, Bundy 2005, Bundy \& Fanning 2005), Georges Bank (Link et al. 2008a) and the Gulf of Maine (Link et al. 2008b). Due to the collapse of Atlantic cod, and dramatic declines of many other species in the Canadian ecosystems of the northwest Atlantic (Bundy et al. 2009), several hypotheses have been developed to explain the functioning of these ecosystems. In particular, 2 independent studies arrived at the conclusion that topdown forcing played a relatively larger role in shaping the eastern Scotian Shelf (ESS) system (Bundy \& Fanning 2005, Frank et al. 2005). In a broader empirical analysis across 26 ecosystems in the North Atlantic, including the Scotian Shelf, Frank et al. (2007) concluded that the default status of marine ecosystems is to be under relatively stronger bottom-up control when undisturbed, but that when exploited, more northerly less diverse and colder ecosystems such as the ESS evolve into systems where top-down control is stronger or more evident. The western Scotian Shelf (WSS) falls midway between the systems that are considered to be under stronger top-down or stronger bottom-up control (Frank et al. 2006, 2007). Of the eastern Canadian ecosystems, the WSS is the least studied. Shackell \& Frank (2007) concluded that while the WSS was more resilient than the ESS due to warmer temperatures, the biomass trajectories of key functional groups were declining, similar to the pattern on the ESS. In a further study, Shackell et al. (2010) proposed that a decline in top predator body size on the WSS resulted in a weakening of top predator pressure and an increase in prey abundance.

In this paper, we focused on the WSS, including the Bay of Fundy, hereafter referred to as WSS/BoF, and took an ecosystem modelling approach to explore some of the hypotheses outlined above. The BoF and WSS (Fig. 1) are located within the Northwest Atlantic Fisheries Organization (NAFO) Divisions 4X and $5 \mathrm{Yb}$. In single-species stock assessments (e.g. 4X cod and $4 \mathrm{X}$ haddock), they are treated as 1 ecosystem. In order to make our work relevant for management purposes, we used this same scale. However, although the 2 areas have a very similar species composition, their dynamics are quite different. The WSS is a wide continental shelf area influenced by currents from Labrador and the Gulf of St. Lawrence and is considered part of the Scotian Shelf Large Marine Ecosystem (LME). This LME is limited in the north by

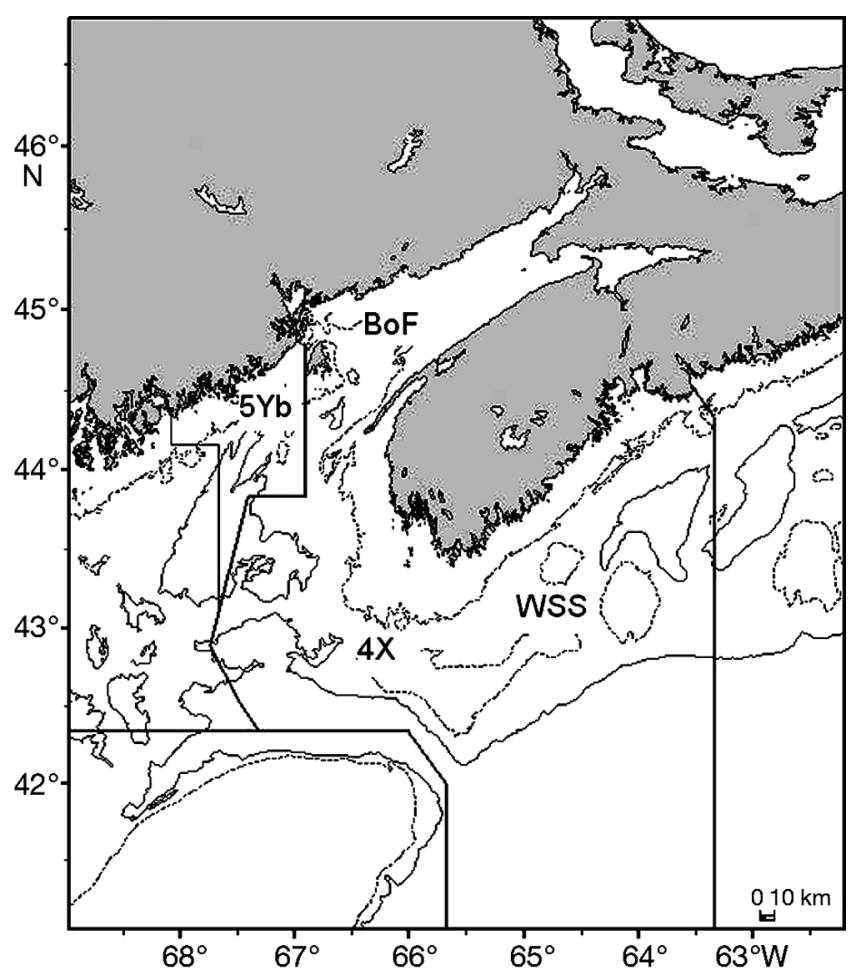

Fig. 1. Model area, comprised of NAFO Divisions 4X and $5 \mathrm{Yb}$, the western Scotian Shelf (WSS) and Bay of Fundy (BoF). Thick black lines: NAFO Division lines, dotted lines: $50 \mathrm{~m}$ depth contours, thin black lines: $100 \mathrm{~m}$ depth contours

the Laurentian Channel and in the south by the Fundian Channel and has a complex topography consisting of shallow banks and basins (Sherman \& Hempel 2008 and references therein). The western part of this LME is characterized by warmer waters compared to the eastern part (Zwanenburg et al. 2002); it has a similar demersal fish fauna (Mahon \& Smith 1989, Zwanenburg et al. 2002, Shackell \& Frank 2003), but higher growth rates and productivity than the east (Frank et al. 2006, Shackell et al. 2010). The main characteristic of the $\mathrm{BoF}$ is the magnitude of its tides, which generate intense vertical mixing caused by bottom turbulence and generate high levels of marine productivity. It is considered part of the Northeast US LME (Sherman \& Hempel 2008 and references therein).

Here, we further developed an Ecopath with Ecosim (EwE) model of the WSS/BoF (Araújo \& Bundy 2011) to explore the structure and functioning of WSS/BoF with respect to the relative roles of a triad of ecosystem drivers: biophysical, exploitative and trophodynamic. EwE enables the multiple aspects of an ecosystem to be modelled in a unified framework (Christensen et al. 2005). Ecosystem models can be used as a tool to (1) identify potential changes in com- 
plex systems that cannot be identified with singlespecies models, (2) emphasize the need to improve knowledge about specific parts of the system, (3) 'test' the compatibility of data sets and (4) serve as a useful basis for the exploration of scientific hypotheses about system structure, dynamics and functioning (Walters \& Martell 2004, Bundy \& Fanning 2005, Araújo et al. 2006). The EwE software (Christensen et al. 2005) is currently the most widely used and tested ecosystem modelling tool for addressing ecosystemlevel responses to changes in fishing harvest strategies and to the influences of climate (Plagányi \& Butterworth 2004, Walters \& Martell 2004). EwE models have been developed for many of the shelf ecosystems in the NW Atlantic (e.g. Bundy 2001, 2005, Link et al. 2008a,b), but there are no EwE models for the WSS/BoF (Fig. 1). Thus, here for the first time, we present the results of a full ecosystem model and address the following questions: (1) What are the relative roles of biophysical, exploitative and trophodynamic drivers in this system? (2) How do the model results contribute to our current understanding of the functioning of this ecosystem? (3) What are the implications for fisheries management?

\section{METHODS}

\section{EwE modelling framework}

EwE is a modelling framework based on assumptions of mass balance and a system of linear equations describing the average flows of mass and energy between functional groups (Christensen et al. 2005). In the Ecopath module, a base model for the system is parameterized for a specific period of time (a snapshot). Ecosim is the time-dynamic module of the package that uses parameters from the Ecopath base model to initiate the dynamic simulations.

The 'mass balance' term in EwE means that the model parameters describing an ecosystem are under the physical constraint that the total flow of mass into a functional group must equal the total flow out of that group. Basic parameter requirements for each functional group include biomass $(B)$, total mortality $(Z)$, production to biomass ratio $(P / B)$, consumption to biomass ratio $(Q / B)$, biomass accumulation rate $(B A)$, total fishery catch $(Y)$ and diet composition. Functional groups can be represented either by aggregate (single) biomass pools or by age/size structured (multi-stanza) components. Predation and energy transfer in Ecosim is modelled using a 'foraging arena hypothesis' where only part of the popula- tion of prey $i$ is vulnerable to predation by predator $j$ at any one time. See Christensen \& Walters (2004), Walters \& Martell (2004), Christensen et al. (2005), Araújo \& Bundy (2011) and Ahrens et al. (2012) for further details. Supplement 1 at www.int-res. com/articles/suppl/m464p051_supp.pdf provides a summary of the main features of the approach.

\section{Model description and data sources}

An Ecopath model of WSS/BoF was first developed to represent the average state of the ecosystem in the years 1995 to 2000, a period for which a wealth of population dynamic parameters and diet data were available (Araújo \& Bundy 2011). This was used as the basis for the Ecopath model for the 1970s, the starting point for the dynamic simulations of past trends with Ecosim.

Whenever possible, the parameters used in the 1995-2000 model were revised using data from the early 1970 s, i.e. for $B, P / B, Z$ and $B A$. The initial percent diet composition for this model was then estimated by Ecopath based on the food preferences from the 1995-2000 balanced model. Since this method is based solely on the relationship between the biomass of prey groups and their proportion in the diets of predators and because the productivity and/or the relative importance of fishing mortality of some functional groups differed between the 2 periods, the 1970 model had to be balanced to account for those differences.

The model comprised 57 functional groups, which included 1 primary producer group, 1 microflora group, 4 zooplankton groups, 13 invertebrate groups, 34 fish groups, 1 seabird group and 3 marine mammal groups. Most fish groups (e.g. cod) were represented by 2 or more life stages to account for ontogenetic shifts in habitat use, feeding behaviour and diet, predation mortality and selective fishing impacts. In addition to the living groups, 2 non-living groups, detritus and discards, were included. The functional groups and species composition and additional information about data sources are given in Supplement 2 at www.int-res.com/articles/suppl/ m464p051_supp.pdf.

The Ecosim simulations were driven by time series of fishing mortalities $(C / B)$ applied to the functional group. However, the biomass series of whales, seals and dogfish were forced since their dynamics are determined at a much larger spatial scale than covered by the model and because of uncertainties in dogfish fishing mortality data. The time series of bio- 
mass, average weight (for stanza groups) and fishing mortalities $(F)$ and catches $(C)$ were estimated using a combination of data sources (Araújo \& Bundy 2011). Additional information and comments on the time series, biomass estimation procedure and the adjustments that were made to the baseline parameters of the 1970 model are given in Supplement 2. The available biomass time series were used in the fitting procedure as relative values. Values of annual biomass accumulation rates (between -0.05 and +0.1 ) were included in many model groups to reflect the fact that they were not in equilibrium conditions.

\section{Ecosim simulations}

We analysed the relative roles of fishing, trophic interactions and biophysical drivers on system dynamics and productivity using a procedure similar to Shannon et al. (2004) and Araújo et al. (2006). The objective was to calculate the total variation explained by the model, using a no-effects model scenario as the base for comparison, and to calculate the relative importance of fishing, trophodynamics and primary productivity (a proxy for biophysical drivers). The Ecosim non-linear tool was used to fit the model biomass estimates to the observed data by estimating vulnerability multipliers $\left(k_{i j}\right)$ (see Supplement 1 ) and simultaneously a primary production anomaly forcing. The sum of squared deviations (SS) of log observed biomass from log predicted biomass was then recorded from the following scenarios: (1) a no-effects model scenario or baseline situation, in which the model estimates are forced to remain constant at the baseline values; (2) all-effects (the estimated $k_{i j}+$ fishing + estimated primary production anomaly); (3) the estimated $k_{i j}+$ fishing only; (4) $k_{i j}+$ estimated primary production anomaly; (5) $k_{i j}$ only; (6) fishing only; and (7) primary production anomaly only. The significance of including the primary production anomaly forcing (Scenario 2) was tested using Scenario 3 as the baseline for comparison (see Christensen et al. 2005 for a description of the significance test).

Since the primary production anomaly scenario does not include all possible forcings on production of some of the key fish species in the system (such as advection of eggs and larvae from nursing areas, match/mismatch of fish larvae and their potential prey, and effects of factors such as temperature on their survival), we also used the non-linear fitting procedure to estimate the $k_{i j}$ parameters for groups composed of multiple life stages driven by fishing mortality and a forcing function applied to egg production (Scenario 8). The forcing functions were constructed using the estimated numbers at recruitment for cod, silver hake, halibut, pollock, haddock and herring, with a lag of $1 \mathrm{yr}$ (cod, halibut, haddock and herring) or 2 yr (silver hake and pollock), depending on data availability.

We then tested the relationship of the primary production anomaly with a suite of potential physical drivers including sea surface temperature (SST) derived from the International Comprehensive Ocean-Atmosphere Data Set (Diaz et al. 2002), water stratification index (R. Pettipas pers. comm.) and the Atlantic Multidecadal Oscillation (AMO) index (Schlesinger \& Ramankutty 1994; www.esrl.noaa. gov/psd/data/timeseries/AMO/; detrended and unsmoothed series). SST has been correlated with primary production and fish recruitment (Beaugrand et al. 2003, Richardson \& Schoeman 2004, Morán et al. 2010); AMO has been correlated with fish recruitment and fish biomass (Gröger \& Fogarty 2011, Shackell et al. 2012), and the water stratification index has been correlated with primary production and pelagic fish biomass (Choi et al. 2004, Head \& Pepin 2010). To ensure that the relationship between a given variable and the primary production series produced by Ecosim was not spurious due to autocorrelation, the data set was 'detrended' by first-order differencing, i.e. the lagged value of the series was subtracted from its current value (Yaffee 2000).

\section{RESULTS}

\section{Overall results}

The model including all effects explained $46 \%$ of the observed variation in biomass of the no-effects model (Table 1). The estimated $k_{i j}$ parameters accounted for $22 \%$, fishing accounted for $13 \%$, and the primary production anomaly forcing for $11 \%$. The reduction in the overall SS caused by the inclusion of the primary production anomaly was considered statistically significant (Scenario 2 versus Scenario $3 ; \mathrm{p}<0.01)$. A more detailed comparison among the main scenarios $(2-5,8)$ is presented in Table 2 and Fig. 2. Of the total number of estimated time series of biomass, Scenario 2 performed better than Scenarios 3, 4, 5 and 8 in 69, 67, 82 and $51 \%$ of the fitted groups, respectively. Series for which the difference in total variance explained between scenarios was $\leq 5 \%$ represented $23 \%$ of the series when comparing Scenarios 2 and 3, 31\% between Scenarios 2 
Table 1. Ecosim runs with the respective sum of squared deviations (SS) of log observed biomass from log predicted biomass. In the no-effects scenario, the model estimates are forced to remain constant at the baseline values; in the alleffects scenario, the model is run including the estimated $k_{i j}$ (vulnerability multipliers), time series of fishing and the estimated primary production (PP) anomaly forcing. In the egg production run, the groups composed of multiple life stages are driven by fishing mortality, forcing functions applied to egg production and a different set of estimated $k_{i j}$

\begin{tabular}{|llcc|}
\hline Scenario & Scenario description & SS & $\%$ variance \\
\hline 1 & No-effects & 498 & \\
2 & All effects & 269 & 46 \\
3 & Fishing $+k_{i j}$ & 323 & 35 \\
4 & PP anomaly $+k_{i j}$ & 305 & 39 \\
5 & $k_{i j}$ only & 389 & 22 \\
6 & Fishing only & 432 & 13 \\
7 & PP anomaly only & 444 & 11 \\
8 & Egg production & 270 & 46 \\
\hline
\end{tabular}

and 4, $8 \%$ between Scenarios 2 and 5, and 23\% between Scenarios 2 and 8. Groups for which the performance of Scenario 2 was always better than the other 4 scenarios comprised $36 \%$ of all fitted time series. These included adult pollock, demersal piscivores, macrozooplankton, the 2 herring stanzas, shrimps, the 2 skate stanzas, mackerel, haddock $3+$ and others (Table 2). For some groups, the amount of variance explained was always lower than $10 \%$, i.e. none of Scenarios 1 to 8 fitted these groups well. The proportion of such groups was lowest in Scenario 2, followed by Scenario 8. Groups with the best results are those with a temporal trend characterized by a typical, rather smooth '1-way trip' (Table 2, Fig. 2).

Since Scenarios 2 to 5 were 'nested', i.e. the $k_{i j}$ parameters were estimated as part of the same procedure, a progressive decrease in overall performance is expected as the drivers are removed. The alternative scenario (8) explained the same amount of variance as Scenario 2, but produced a different set of $k_{i j}$ parameters, implying different mechanisms to 'explain' the observed variation. In about $37 \%$ of the series, the difference between the SS from the 2 scenarios was $\leq 10 \%$. In cases where the egg-forcing scenario performed better, the larger differences were observed for biomass series of large pelagic fish, flounders, cod 4-6 yr, juvenile haddock and lobsters (Fig. 2). It is worth noting that for herring, despite large observed variations in recruitment, the egg-forcing in Scenario 8 did not improve the model fit. A similar situation occurred for haddock; Scenario 8 improved the fit for juvenile haddock, but the primary production anomaly scenario performed better for adult haddock (see below).
Table 2. Relative quality of the model fits in different scenarios relative to Scenario $1\left(\mathrm{SS}_{\mathrm{n}} / \mathrm{SS}_{1}\right.$ ratio, where $\mathrm{SS}$ is the sum of squared deviations). Group series are in increasing order of ratios obtained with Scenario 2. Scenarios: $1=$ no-effects model $_{i} 2=$ all-effects (fishing $+k_{i j}+$ primary production forcing); $3=k_{i j}+$ fishing; $4=k_{i j}+$ primary production forcing; $5=$ $k_{i j i} 8=$ fishing $+k_{i j}+$ egg-production forcing. Scenarios 2 to 5 share the same set of $k_{i j}$, whereas in Scenario 8, these parameters were estimated independently. See Supplement 2 at www.int-res.com/articles/suppl/m464p051_supp.pdf for a description of the functional groups

\begin{tabular}{|c|c|c|c|c|c|c|}
\hline \multirow[t]{2}{*}{ Rank } & \multirow{2}{*}{ Group } & \multicolumn{5}{|c|}{ Scenario } \\
\hline & & 2 & 3 & 4 & 5 & 8 \\
\hline 1 & Cod $7+$ & 0.06 & 0.06 & 0.21 & 0.49 & 0.03 \\
\hline 2 & Sharks & 0.06 & 0.05 & 0.19 & 0.37 & 0.05 \\
\hline 3 & Cod 4-6 & 0.21 & 0.23 & 0.24 & 0.51 & 0.10 \\
\hline 4 & Cod 1-3 & 0.22 & 0.40 & 0.28 & 0.59 & 0.14 \\
\hline 5 & Pollock 4+ & 0.22 & 0.27 & 0.54 & 0.85 & 0.25 \\
\hline 6 & D piscivores & 0.26 & 0.51 & 0.28 & 0.47 & 0.67 \\
\hline 7 & Flounders & 0.27 & 0.13 & 0.66 & 0.30 & 0.11 \\
\hline 8 & Pollock $<4$ & 0.30 & 0.31 & 0.33 & 0.67 & 0.29 \\
\hline 9 & L sculpin 25 & 0.34 & 0.28 & 0.23 & 0.41 & 0.26 \\
\hline 10 & $\operatorname{Cod}<1$ & 0.35 & 0.55 & 0.47 & 0.81 & 0.18 \\
\hline 11 & S Hake 4+ & 0.38 & 0.91 & 0.29 & 0.79 & 0.41 \\
\hline 12 & Macrozooplankton & 0.45 & 1.04 & 0.45 & 1.03 & 1.01 \\
\hline 13 & Lobster & 0.47 & 0.40 & 1.69 & 1.36 & 0.38 \\
\hline 14 & Herring 4+ & 0.47 & 0.64 & 0.59 & 0.76 & 0.82 \\
\hline 15 & Shrimps & 0.49 & 0.94 & 0.55 & 1.00 & 0.88 \\
\hline 16 & Scallop & 0.52 & 0.55 & 0.39 & 0.39 & 0.53 \\
\hline 17 & Large pelagic & 0.52 & 0.24 & 0.49 & 0.31 & 0.16 \\
\hline 18 & Skates $49+$ & 0.53 & 0.76 & 0.69 & 0.94 & 0.81 \\
\hline 19 & Other pelagic & 0.64 & 1.25 & 0.48 & 0.74 & 1.09 \\
\hline 20 & Mackerel & 0.66 & 0.77 & 0.77 & 0.79 & 0.76 \\
\hline 21 & Haddock 3+ & 0.68 & 0.89 & 1.30 & 0.99 & 0.74 \\
\hline 22 & Halibut $82+$ & 0.71 & 0.50 & 1.21 & 0.84 & 0.49 \\
\hline 23 & Skates <49 & 0.72 & 0.73 & 0.90 & 0.91 & 0.85 \\
\hline 24 & Halibut $<46$ & 0.73 & 0.93 & 0.82 & 1.01 & 0.80 \\
\hline 25 & Herring $<4$ & 0.75 & 0.91 & 0.76 & 0.93 & 0.82 \\
\hline 26 & Redfish $22+$ & 0.77 & 0.83 & 0.87 & 0.94 & 0.86 \\
\hline 27 & A plaice $26+$ & 0.83 & 0.59 & 0.77 & 1.61 & 0.76 \\
\hline 28 & Halibut 46-81 & 0.85 & 0.96 & 0.82 & 0.90 & 0.94 \\
\hline 29 & Haddock <3 & 0.85 & 0.95 & 1.11 & 1.00 & 0.34 \\
\hline 30 & Squids & 0.90 & 0.99 & 0.90 & 0.99 & 0.96 \\
\hline 31 & S Hake 2-3 & 0.94 & 1.38 & 0.80 & 1.18 & 1.06 \\
\hline 32 & Large crabs & 0.95 & 1.01 & 0.99 & 1.00 & 1.02 \\
\hline 33 & L sculpin $25+$ & 0.95 & 1.60 & 1.25 & 2.51 & 0.65 \\
\hline 34 & $\mathrm{~L}$ benthivores & 0.97 & 1.03 & 1.12 & 1.05 & 1.08 \\
\hline 35 & Redfish $<22$ & 0.98 & 0.94 & 1.00 & 0.96 & 0.97 \\
\hline 36 & S-m benthivores & 1.07 & 1.06 & 1.00 & 1.00 & 1.06 \\
\hline 37 & S Hake <2 & 1.13 & 0.94 & 1.10 & 0.88 & 0.56 \\
\hline 38 & Mesozooplankton & 1.78 & 0.97 & 1.77 & 0.97 & 0.99 \\
\hline \multirow[t]{4}{*}{39} & A plaice $<26$ & 2.53 & 1.85 & 1.03 & 1.04 & 2.52 \\
\hline & Median & 0.66 & 0.83 & 0.77 & 0.91 & 0.76 \\
\hline & Mean & 0.68 & 0.75 & 0.75 & 0.88 & 0.68 \\
\hline & $\% \leq 0.5$ & 38.5 & 28.2 & 33.3 & 17.9 & 35.9 \\
\hline \multicolumn{7}{|c|}{ Colour codes: } \\
\hline$\leq 0.30$ & $0.31-0.60 \quad 0.61$ & & 0.91 & & & \\
\hline
\end{tabular}



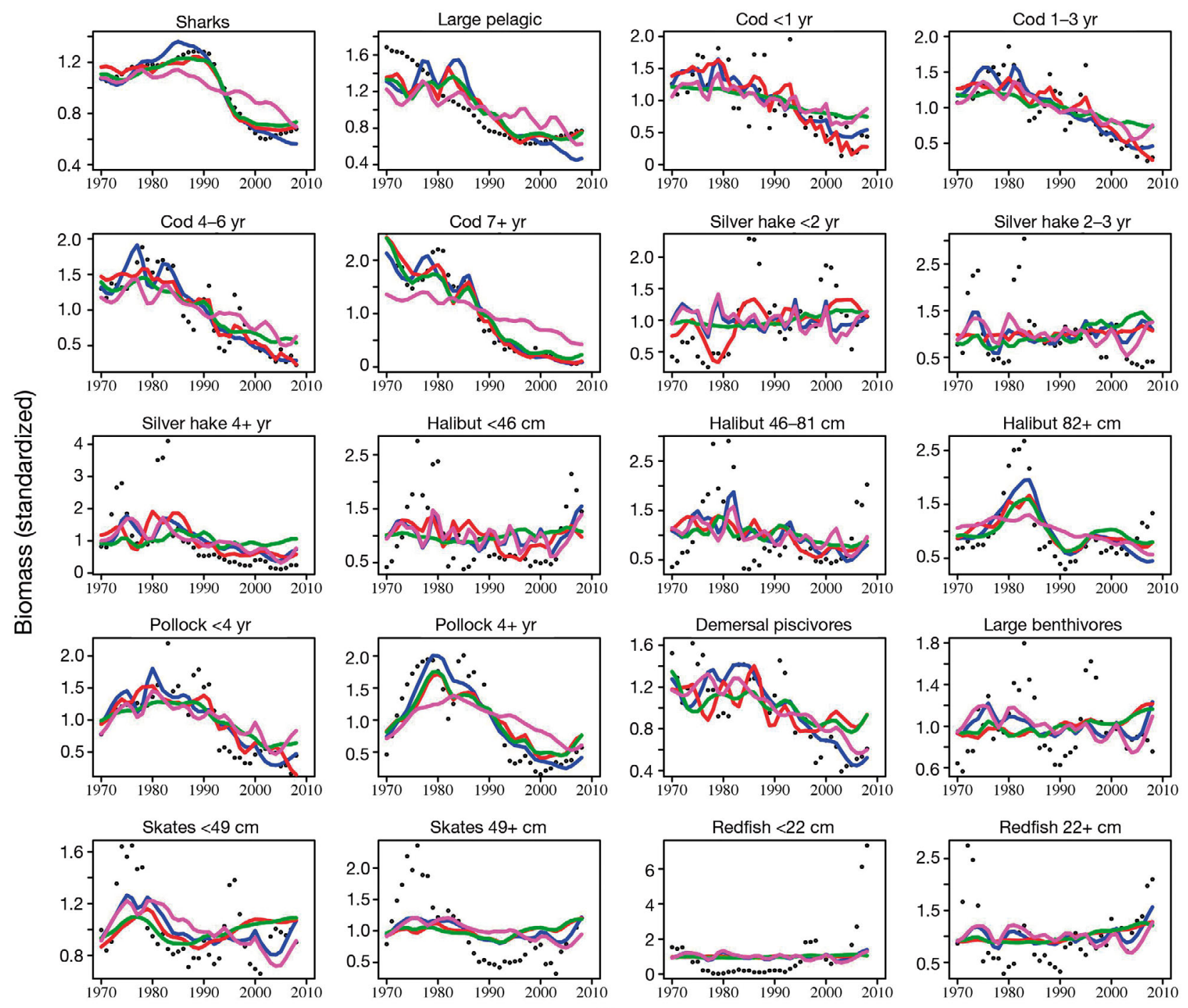

Fig. 2. Biomass (standardized) time series estimates for the western Scotian Shelf and Bay of Fundy ecosystem from 1970 to 2008. Black dots represent data to which model estimates were fitted; blue lines: Ecosim Scenario 2 (kij + fishing + primary production anomaly, where kij represents the vulnerability multipliers); green lines: Scenario 3 (kij + fishing); magenta lines: Scenario 4 (kij + primary production anomaly); red lines: Scenario 8 (egg production). Phytoplankton were not fitted to the data, but the observed data are shown for comparative purposes (black dots). See Supplement 2 at www.int-res.com/ articles/suppl/m464p051_supp.pdf for a description of the functional groups

The $k_{i j}$ parameters in these 2 scenarios were estimated for a total of 35 consumers. For $21(60 \%)$, the $k_{i j}$ parameters estimated in the egg-forcing scenario differed from the primary production anomaly scenario by an amount of $\pm 50 \%$. For 8 consumers, the differences were about 10 -fold or more. For these 8 consumers, the primary production anomaly scenario performed better. These large differences were diminished by setting an upper limit of 10 or 100 to the vulnerability multipliers, since the higher values did not improve the fitting significantly and resulted in an unstable model when run in a no-fishing scenario.
The results presented herein refer to the models with constrained $k_{i j}$ parameters.

The primary production anomaly forcing scenario predicted a long-term decrease in primary production with values mostly above average until the end of the 1980s and mostly below average afterwards. The trend was then reversed after 2002. The latter years of this simulation map well onto continuous plankton recorder (CPR) data (note these data were not used for fitting - see estimated phytoplankton series in Fig. 2). A similar pattern was predicted for low trophic level groups in Scenario 8, but was not 

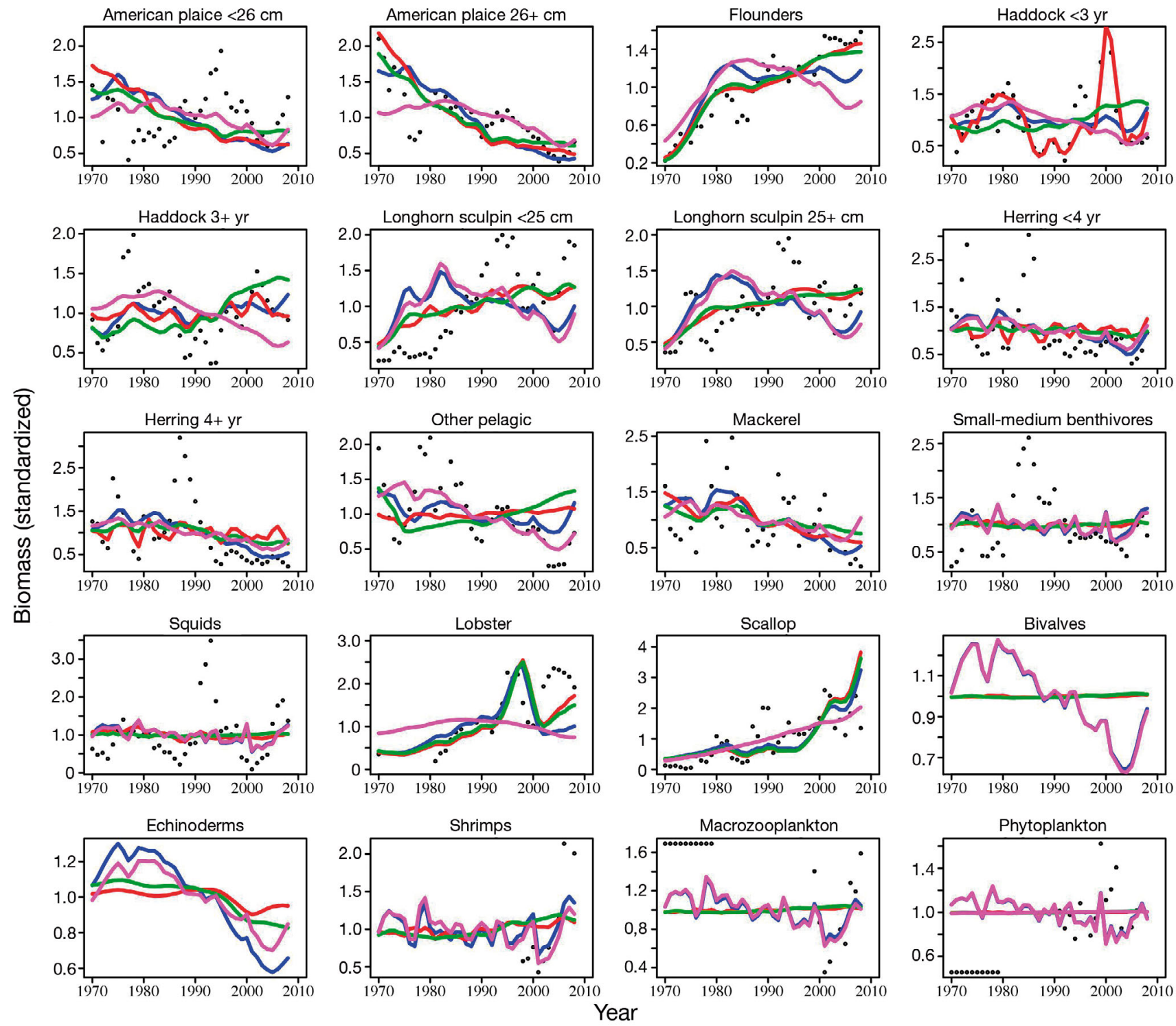

Fig. 2 (continued)

observed for the non-commercial lower trophic levels in the other scenarios (Fig. 2).

Regressions of the predicted time series of primary production on physical variables were significant for $\mathrm{SST}$, the stratification index and the AMO. Among the SST series explored, significant correlations were found for the Scotian Shelf LME (January to April) time series (Table 3). Similar correlations were obtained between these physical indices and the simulated macrozooplankton group, which is composed mainly of euphausiids, 1 of the main forage taxa in the system (not shown).

The estimated aggregated resident fish biomass (driven only by the primary production anomaly with fishing mortality estimates kept at baseline levels;
Scenario 4) was highly correlated with observed biomass (Fig. 3). All regressions of the simulated fish biomass against the physical indices reported above were negative and significant $(p<0.05)$; the strongest correlation was found for the AMO index (Fig. 3).

EwE captured the main trends in abundance and mortality for most species. However, the dynamics of herring and haddock were not well modelled, which is surprising since these are among the better studied species in the model. Although the dynamics of cod were captured well by the model, this was achieved using a 'fake' mortality term (Clark \& Emberley 2009, see Supplement 2). Since these species have important roles as prey or predator, we focused on Scenar- 
Table 3. Relationship between the primary production series from 1970 to 2008 generated by Ecosim and key environmental variables. SST (LME): January to April surface temperature time series, derived from the International Comprehensive Ocean-Atmosphere Data Set (Diaz et al. 2002); WSS/BoF: western Scotian Shelf and Bay of Fundy; AMO: Atlantic Multidecadal Oscillation index (Schlesinger \& Ramankutty 1994). The series used is the long-term linearly detrended data (www. esrl.noaa.gov/psd/data/timeseries/AMO/)

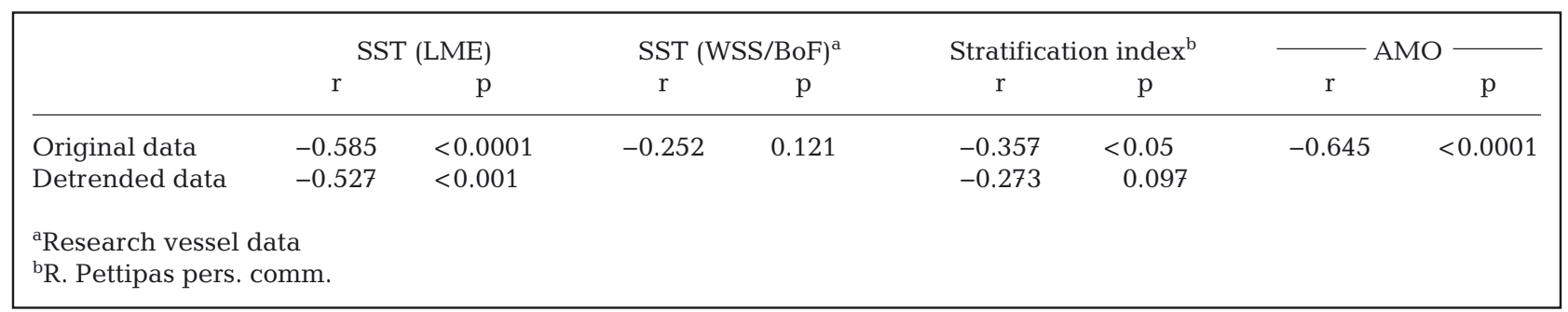

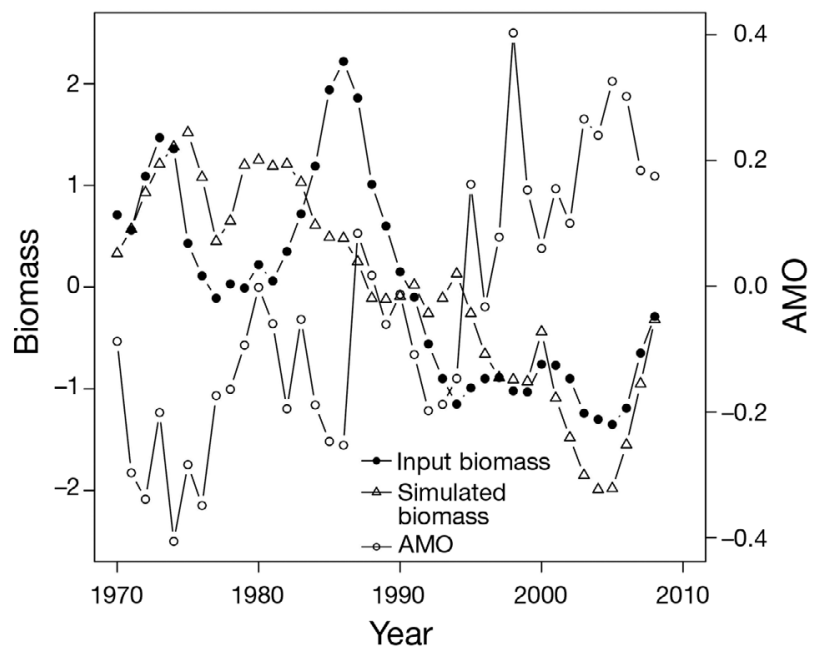

Fig. 3. Comparison of results from Scenario 4 for main resident fish species, i.e. excluding large pelagics, sharks and dogfish, driven by the primary production anomaly forcing and constant fishing (baseline) mortality with the Atlantic Multidecadal Oscillation (AMO) index. Input biomass estimates refer to data used in the time series fitting. The estimated biomass was highly correlated with observed biomass $(r=0.70, p<0.0001)$. The AMO index was negatively correlated with the simulated series $(r=-0.810, p<0.0001)$ and input series $(\mathrm{r}=-0.642, \mathrm{p}<0.0001)$.

ios 2 and 8 to further examine these results and explore reasons for the lack of fit, investigating processes such as changes in recruitment (productivity), changes in condition and natural (unexplained) mortality of fish groups.

\section{Herring}

Herring has high recruitment variability: virtual population analysis (VPA) estimates indicate that herring had 4 main recruitment events $(1971,1978$, $1983,1984)$, which were more than double the longterm average recruitment (M. Power pers. comm.).
Although the egg-forcing scenario used this information, the inter-annual variability in herring abundance was not well captured (Figs. $3 \& 4$ a). To further improve this fit, the vulnerability multipliers $\left(k_{i j}\right)$ of the prey items of both small and large herring were increased, and the feeding time adjustment parameters of both herring stanzas were changed from 0.5 to 0 (Fig. 4a). The feeding time adjustment rate influences how predation mortality varies with time: a value of 0 implies a constant risk of predation (Christensen et al. 2005). For juvenile herring, changing feeding time to 0 significantly improved the fit of Ecosim total mortality estimates compared to the VPA total mortality estimates (feeding time $=0.5, \mathrm{r}=$ $0.076, p=0.644$; feeding time $=0, r=0.51, p<0.001$ )

The fit of estimated adult herring biomass to observed biomass also improved, but was consistently higher since 1992 (Fig. 4a), which may be due to changes in condition (Fig. 4b). Based on VPA estimates, the relationship between adult herring average weight and abundance has changed over time. From 1970 to the mid-1980s, there was a negative relationship between average weight and biomass, indicating density-dependent compensation in weight. Since then, the average weight has decreased even in times of low abundance, which was not captured by EwE.

\section{Haddock}

The best results for haddock were obtained with the egg-forcing scenario, which was driven by aboveaverage recruitment in 1973, 1975-1983, 1998-2001, 2004 and 2007 (random-walk- $M$ VPA, where $M$ is the instantaneous natural mortality; R. K. Mohn pers. comm.). This scenario performed especially well for the biomass series of the haddock $<3$ stanza (Fig. 5). However, Ecosim did not capture the peak in adult haddock biomass in the 1970 s, or the trough in the 


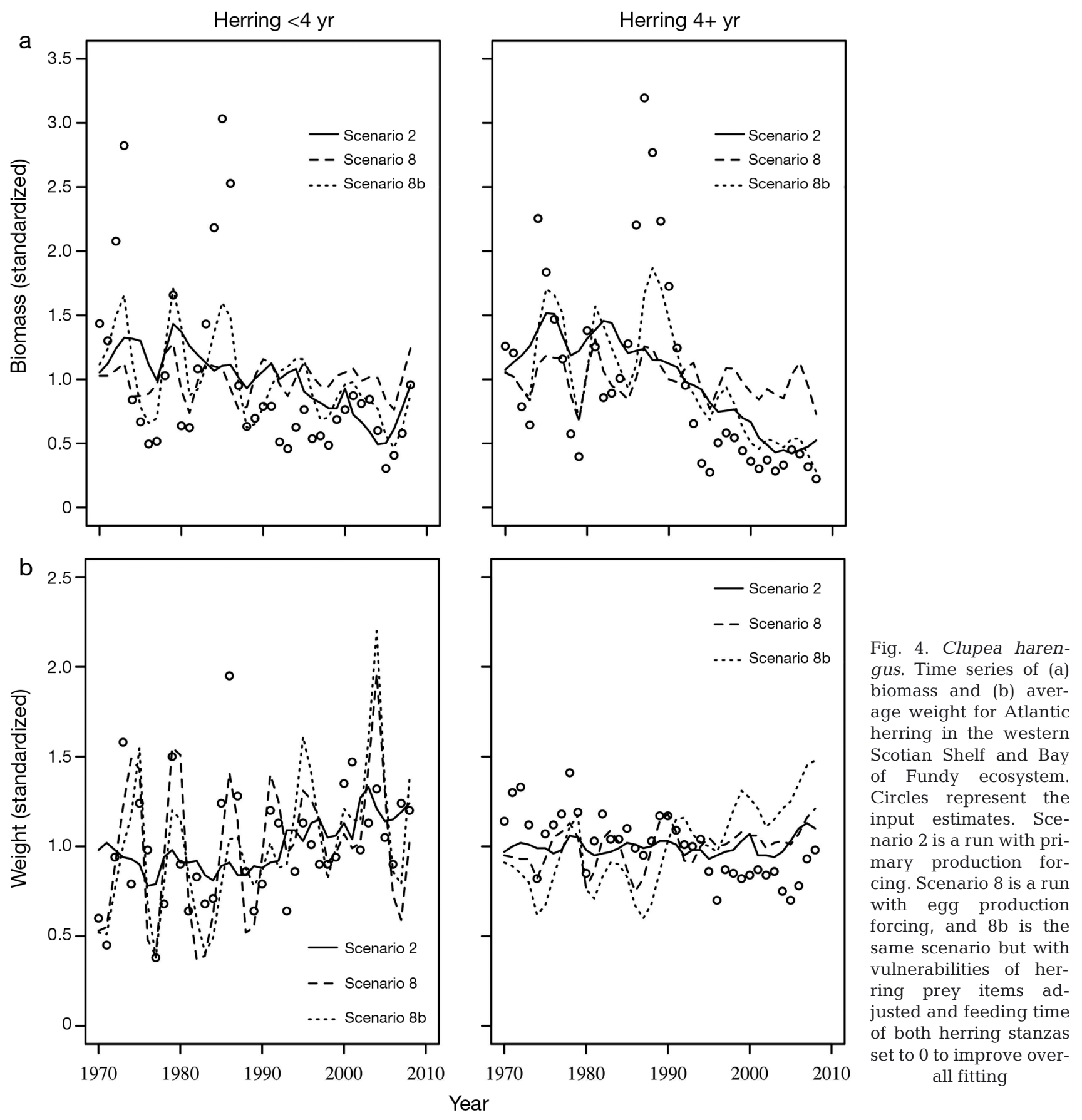

mid-1980s to the mid-1990s, which may have been related to changes in condition.

Highest recruitment occurred in 1999 and 2000, during years of below-average adult condition, and adult numbers peaked in 2001 to 2006. However, peak biomass occurred in the 1970 s because adult haddock condition was higher (Fig. 6). Hence the observed increase in haddock numbers during the 2000s was not 'translated' into biomass gains, partially because of poorer condition. This is not cap- tured very well by the model, partially because average weight was under-estimated from the mid1970s to the mid-1980s (Fig. 6, haddock 3+, r $=0.475$, $\mathrm{p}<0.01$ ).

\section{Cod}

Overall, cod biomass estimates from the 2 scenarios fit the observed data quite well, with the egg-forcing 


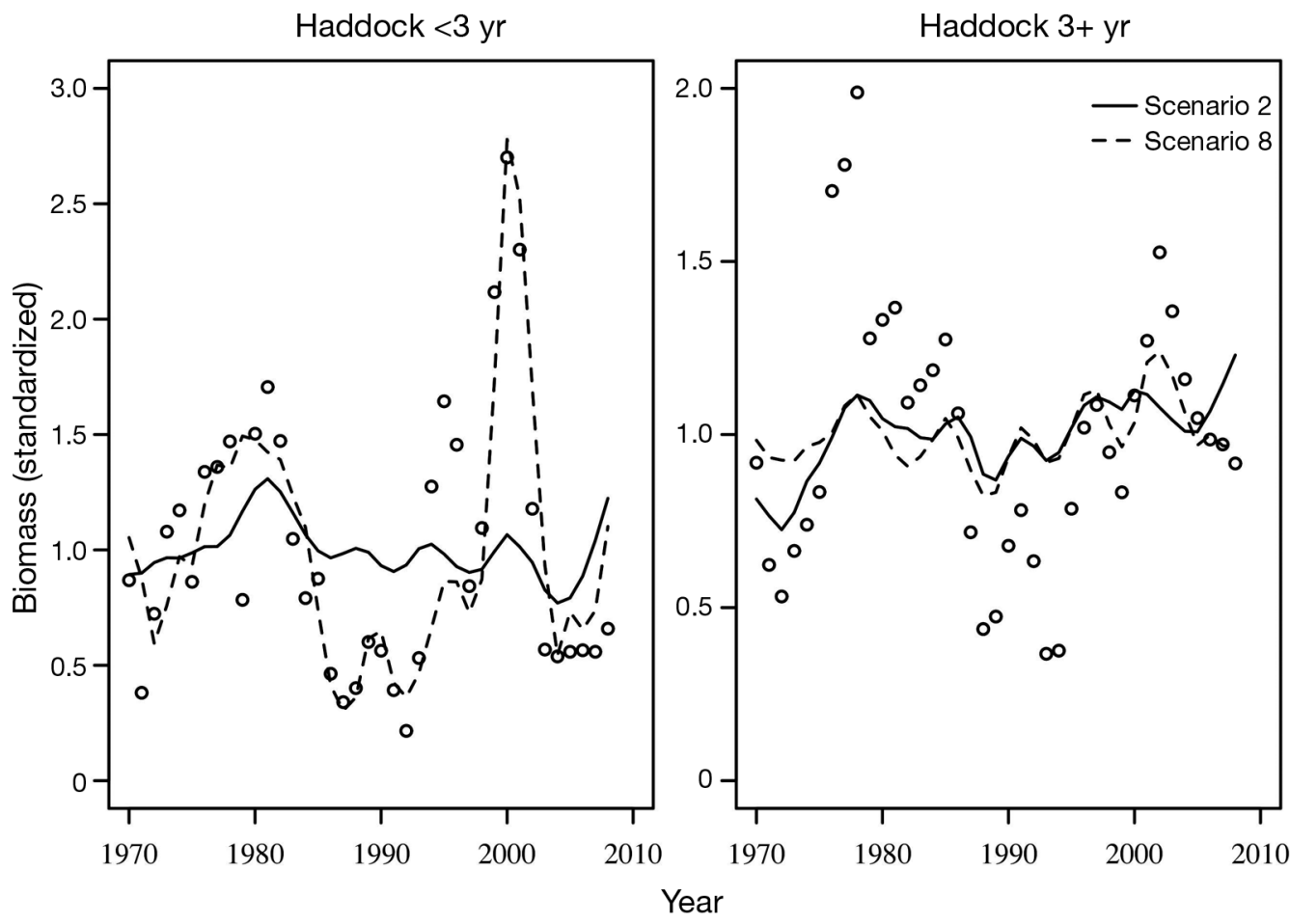

Fig. 5. Melanogrammus aeglefinus. Biomass time series for haddock in the western Scotian Shelf and Bay of Fundy (WSS/ BoF) ecosystem. Circles represent the input estimates. Scenario 2 is a run with primary production forcing and Scenario 8 with egg production forcing

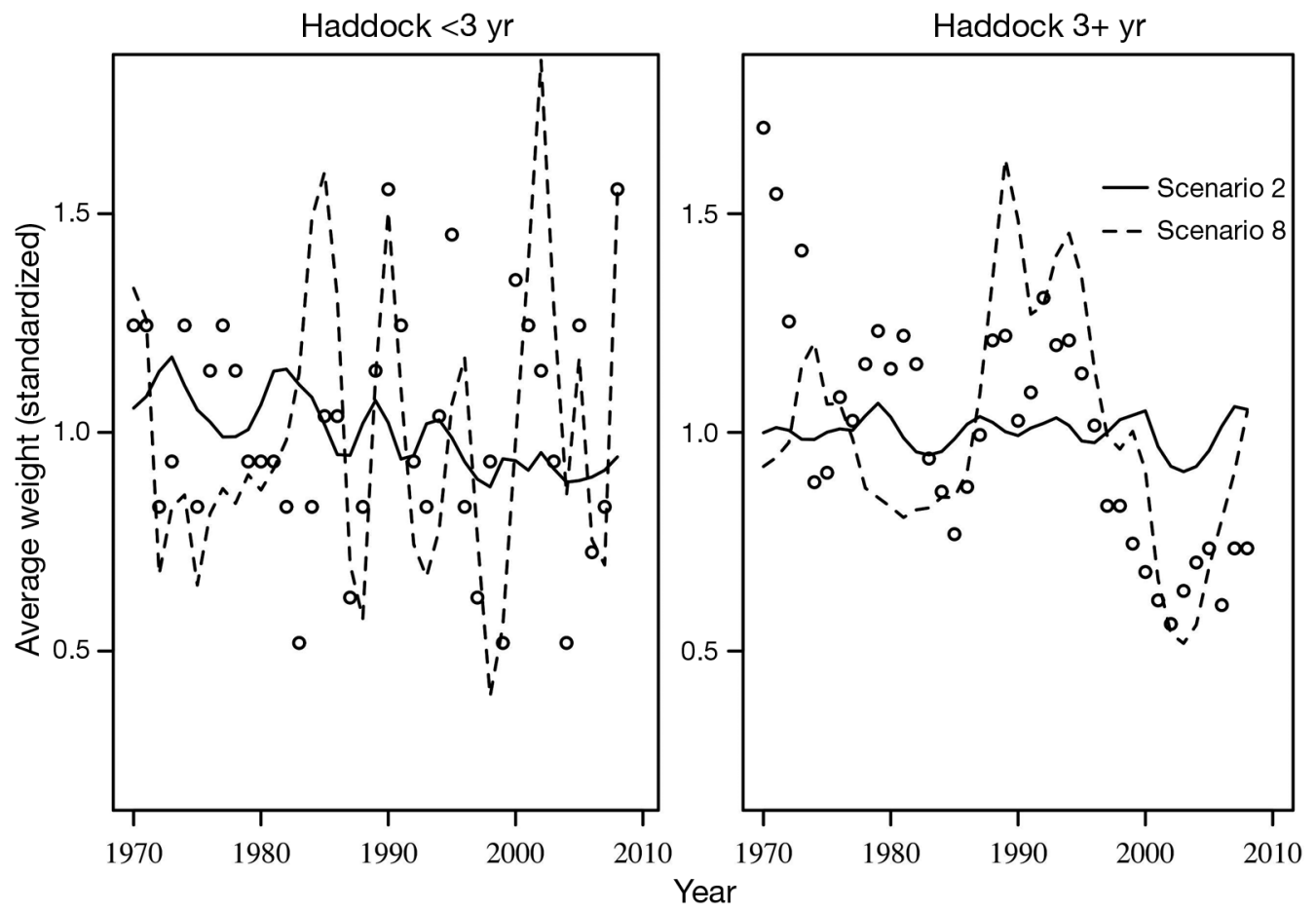

Fig. 6. Melanogrammus aeglefinus. Time series for haddock average weight in the western Scotian Shelf and Bay of Fundy (WSS/BoF) ecosystem. Circles represent observed data; lines are estimates from the Ecosim scenario run with egg production forcing functions. Scenario 2 is a run with primary production forcing and Scenario 8 with egg production forcing

scenario performing slightly better (Fig. 2). The largest differences between the 2 scenarios were related to the first 2 stanzas. However, we employed a 'fix' in this model, following the VPA method (Clark \& Emberley 2009) to account for the high mortality of adult cod, which remained high despite the severe cuts in cod catches. We used 'fake' fishing mortality rates, produced by adding 0.5 to the actual fishing mortality, for the years that VPA $M$ was set equal to $0.7 \mathrm{yr}^{-1}$. Although the cause of this high unexplained mortality is unknown, a working hypothesis is that it is due to predation by seals (see Trzcinski et al. 2009). 
To test the effects of hypothetical seal predation on adult cod, we ran 2 additional scenarios where adult cod stanzas were driven by the actual fishing mortality and (1) seal diet was composed of $7 \%$ of cod $4-6$ yr and $7 \%$ of cod $7+y r$ and (2) seal diet was composed of $14 \%$ of cod $4-6 \mathrm{yr}$ and $14 \%$ of $\operatorname{cod} 7+\mathrm{yr}$. The estimates from these scenarios were compared to the results for a run in which adult cod stanzas were driven by the actual fishing mortality and there was no seal predation on these age groups (Fig. 7). The best fits to the VPA estimates were obtained with the scenario with the highest level of predation $(\mathrm{r}=0.807$ for $\operatorname{cod} 4-6 ; r=0.869$ for $\operatorname{cod} 7+$ ).

\section{DISCUSSION}

Marine ecosystems are complex, non-linear and dynamic, and are subject to a triad of external and internal drivers (fisheries exploitation, biophysical and trophodynamic factors, Link et al. 2010). By reducing the complexity of the ecosystem to 57 functional living groups in a trophodynamic model, we were able to reproduce many of the observed dynamics in the WSS/BoF ecosystem and explore the relative strength within the triad of drivers. Furthermore, where we were not able to reproduce observed trends, we investigated plausible explanations which shed further light on the dynamics and drivers in this system.

\section{What are the relative roles of biophysical, exploitative and trophodynamic drivers in this system?}

The trophic flow parameters explained most of the variance in the biomass series; the magnitude of the effects of fishing and biophysical forcing of primary production was similar. Here, the biophysical driver was modelled as an anomaly in primary production, generated by a model fitting routine. As an alternative to that approach, we also fitted the model by driving some groups with an egg-production forcing function. The egg-production scenario improved the fit for a few problematic groups, and the total amount of variance explained was very similar to the primary production scenario. Results from these 2 scenarios indicate that there are processes at the bottom of the food web that are not accounted for when only fishing and trophic flow parameters are used to drive the simulations. Although the overall fit for the 2 'best' scenarios was very similar, important differences in the estimated $k_{i j}$ parameters were observed for some groups. These differences imply that (1) different functional groups, species or life stages are subject to different forcings (Gaichas et al. 2011) and (2) there can be multiple solutions to these large underdetermined models (Araújo et al. 2006, Mackinson et al. 2009b).

Our results suggest a link between primary production and climate change. However, driving the

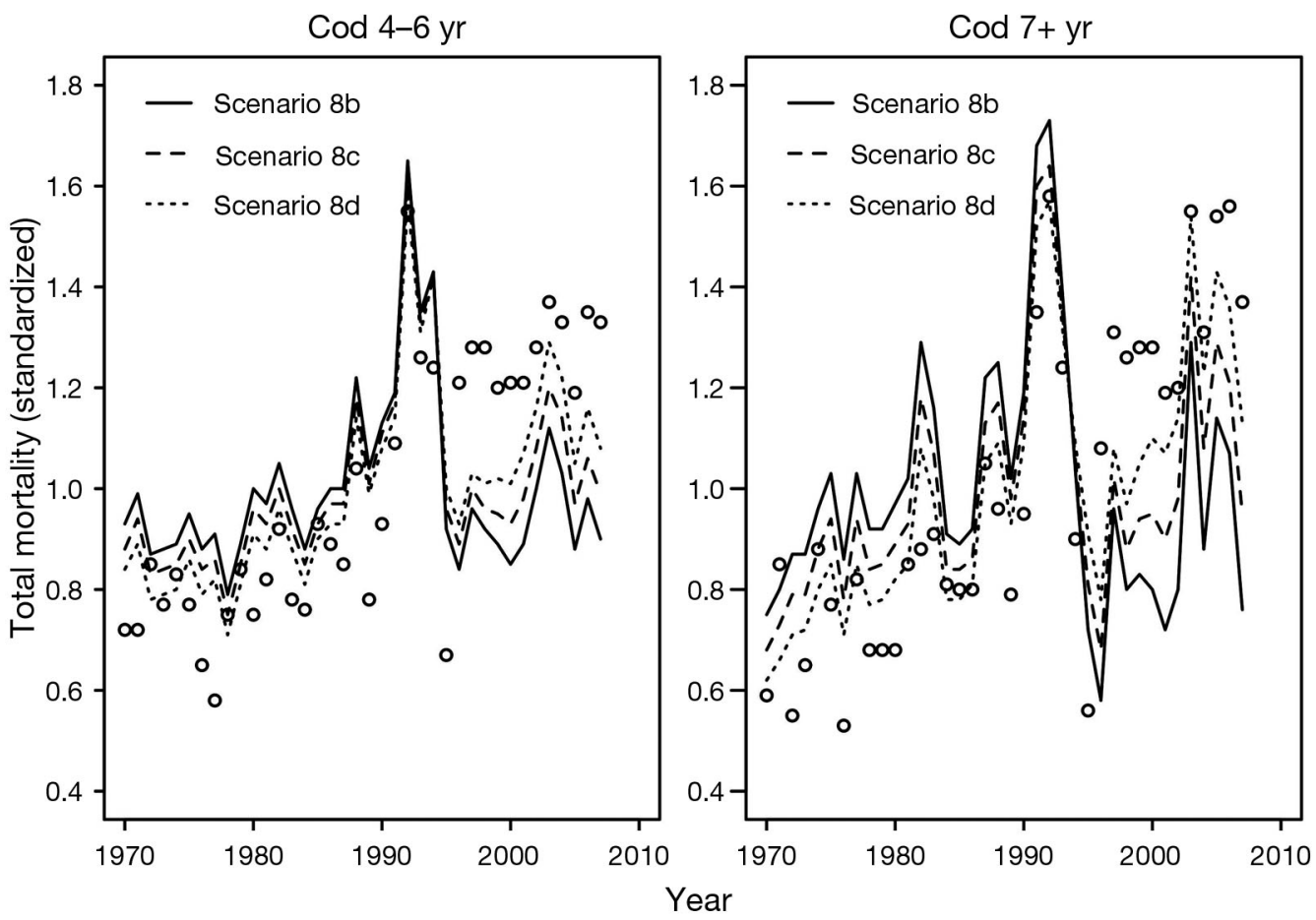

Fig. 7. Gadus morhua. Times series of total mortality for the 2 adult cod stanzas in the western Scotian Shelf and Bay of Fundy (WSS/ BoF) ecosystem. Circles represent estimates from virtual population analysis. Ecosim estimates are derived from runs with egg production forcing (see 'Methods' for further details); Scenario $8 \mathrm{~b}$ is a run with no predation by seals; $8 \mathrm{c}$ is a run with seal diet composed of $7 \% \operatorname{cod} 4-6 \mathrm{yr}$ and $7 \%$ $\operatorname{cod} 7+\mathrm{yr}$, and $8 \mathrm{~d}$ is a run with seal diet composed of $14 \% \operatorname{cod} 4-6 \mathrm{yr}$ and $14 \% \operatorname{cod} 7+\mathrm{yr}$ 
model by forcing primary production is a broadbrush approach which we would not expect to work well for all groups. Since thermal preferences differ among species, some will have trends that do not match the 'average' or main trend. Also, groups with high and apparently chance recruitment variation, driven by a combination of factors such as predation, physically induced mortality, food supply and/or advective loss from nursery areas (Platt et al. 2003, Buckley et al. 2004), will have weaker correlation with the main signal. The fits of haddock and herring were improved when their dynamics were driven by the egg-forcing scenario. Both species have a few very strong and extraordinary year classes which are difficult to predict. The combination of factors described above may result in strong and random variations in recruitment that cannot be tracked by the primary production forcing function, since it tracks the shared anomalies in the biomass series (Walters \& Martell 2004). It is crucial then to determine whether it is reasonable to include a primary production forcing that influences the estimates of the trophic flow parameters, and thus species interactions, for all groups, or whether a more selective approach would be more effective (Gaichas et al. 2011).

Fishing may alter the responses of exploited populations and ecosystems to abiotic factors. At the population level, fishing acts by reducing age groups, changing spatial distribution, and causing the loss of sub-populations and changes in life-history traits (Perry et al. 2010, Planque et al. 2010). It is expected, for example, that populations with truncated age structure will be more sensitive to inter-annual variations in abiotic factors due to the lack of large, more fecund spawners (Longhurst 2002, Wright \& Trippel 2009, Hsieh et al. 2010). This can also increase chance variations in recruitment, which are more common in the short-lived species. On the other hand, unexploited or lightly exploited populations will be more stable and will closely track the longterm climate signals. At the community and ecosystem level, fishing changes species composition and size structure, due to selectively targeting certain species, age groups and fishing grounds (Garcia et al. 2012). Some species are indirectly affected by the reduction of predators, competitors or prey species. Exploited ecosystems are normally composed of relatively large abundances of small species, with fast turnover rates, which respond rapidly to short-term climate variability (Perry et al. 2010). In contrast, in unexploited systems, top predators dampen the effects of environmental variation, similar to the effects of large spawners at the population level. Their removal releases the short-lived prey species, which become more abundant and oscillate more widely due to inter-annual variations. At the aggregated level, biomass is expected to be stable and less susceptible to fishing and/or high-frequency abiotic signals due to redundancy of functional groups and compensatory effects (Link \& Garrison 2002, Perry et al. 2010). Aggregated biomass, however, can be expected to closely track the long-term, slower and broader climate signals that change the system carrying capacity, more so than individual species whose variations are influenced by complex interactions with other species in the system. This is demonstrated by the results of our study, where the observed and simulated resident fish biomass closely tracked the AMO index.

Our model captured most of the observed abundance trends. However, we acknowledge both observation and process uncertainties inherent in this approach. Model uncertainties are highest where there is a lack of data, resulting in poorly estimated parameters, uncertain time series data or poor understanding of dynamics. The latter is the case for groups such as whales, seals and dogfish for which the biomass was forced since their dynamics are determined at a much larger spatial scale than covered by the model.

An on-going conundrum is the high level of 'unexplained' mortality of some fish species, such as adult cod after reductions in fishing quota that took place in the 1990s. The VPA model for the $4 \mathrm{X}$ cod stock uses a knife-edge increase in $M$ for age $4+$ cod from 0.2 to about $0.7 \mathrm{yr}^{-1}$ in 1996 (Clark \& Emberley 2009). We mimicked this in the base scenarios for the time series fitting, then explored the main hypothesis that predation by seals is the cause of this unexplained mortality. Not surprisingly, and as in other studies, increasing seal predation on cod accounts for some of the unexplained mortality (DFO 2011, O'Boyle \& Sinclair 2012). However, there is no evidence of seal consumption of large cod on the Scotian Shelf (Bowen et al. 1993, Bowen \& Harrison 1994), and the amount of cod required in the seal diet to explain this predation implies a very strong selection for this type of prey. The results from this scenario are in agreement with a recent assessment of cod-seal interactions, which was unable to explain the high adult cod mortality rate (Trzcinski et al. 2009). Part of the high mortality could be also related to unreported fishing mortality; however, it is believed that this is not a major factor (Clark \& Emberley 2009). This high unexplained mortality is not unique to cod or to the 
WSS/BoF; several demersal species have high unexplained mortality across eastern Canada (DFO 2003, Benoît \& Swain 2008, Swain 2011), challenging our understanding of their biology and ecology.

\section{How do the model results contribute to our current understanding of the functioning of this ecosystem?}

Our results indicate a decrease in primary production from the late 1970 s to the early 2000s. This contrasts with the observed significant increase in average decadal diatom abundance sampled by the CPR program on the western Scotian Shelf from the 1970s to the 1990s (Head \& Pepin 2010). Using data dating from 1950, Boyce et al. (2010) estimated a basin-wide decrease in phytoplankton concentration for the North Atlantic and globally. Similarly, Gregg et al. (2003) estimated a global and North Atlantic basinwide decrease in primary production by 6.3 and $6.7 \%$, respectively, between 1979/1986 and 1997/ 2002. Steinacher et al. (2010) predicted a decrease in phytoplankton in the future for the NW Atlantic and globally. All 3 studies indicate a basin-wide negative correlation between SST and primary production for the North Atlantic and in the latitude range where the WSS/BoF system falls.

There are several reasons why the Ecosim predictions may differ from the results of Head \& Pepin (2010) for phytoplankton: (1) The CPR sampling coverage for the Scotian Shelf in the 1970s was very poor. (2) Most of the recorded increase in the CPR phytoplankton took place over the winter months, producing increased average decadal estimates in the 1990s and 2000s. Since zooplankton are not abundant in the winter months, most phytoplankton production would either sink to the bottom or be driven away from the system by advective processes, and be lost to higher trophic levels (Head \& Pepin 2010). (3) The decrease in primary production predicted by Ecosim is a consequence of the primary production anomaly. The latter is generated by the model when fitting the model to the predominately higher trophic level time-series data. Most of the biomass time series for these higher trophic levels have decreased since the mid-1980s due to fishing, sending a strong signal. If these higher trophic levels were not modelled well enough (i.e. top-down effects of fishing), then the primary production anomaly may have artificially improved the fit by reducing primary production. (4) It is a model artefact resulting from poor representation of processes of highly aggregated groups at low trophic levels in Ecosim.
The primary production anomaly generated by Ecosim was negatively correlated with SST (January to April), the stratification index and the AMO index. Stratification may have both positive and negative effects on phytoplankton production (Gargett 1997, Song et al. 2011): positive effects may result from restricted vertical water exchange and increased stability of the water column which maintains cells in the region of optimum light incidence, although this may also have the negative outcome of reducing the supply of inorganic nutrients from deeper waters below. A consequence of these opposite effects is that there will be an optimum window for production, which is associated with a combination of nutrient and light supply that is favourable for peak production. Steinacher et al. (2010) predicted that increased SST and correlated stratification could lead to decreased phytoplankton production due to reduced input of macro-nutrients from deeper waters into the euphotic zone for most of the North Atlantic. In a modelling study, Song et al. (2011) also concluded that productivity is unlikely to increase with increased SST and correlated stratification. Using a 1D planktonic ecosystem model for the Nova Scotia shelf and Gulf of Maine regions for 1984 to 2007, they concluded that (1) stratification can lead to early spring phytoplankton blooms and late fall blooms and (2) the variations in the timing of the spring bloom and the alleviation of light limitation have little positive effect on the magnitude of annual productivity in these regions. According to Song et al. (2011), the weak positive correlation between stratification and annual productivity are consistent with the fact that these systems lie in a transition zone between predominant nutrient limitation (low latitude, nonupwelling systems) and light limitation (prevalent at high latitudes). They concluded that 'variations in fisheries productivity are likely secondary to the profound changes in recruitment that can occur due to changes in bloom timing' (Song et al. 2011, p. 115)

AMO is a large-scale pattern of multidecadal variability in SST of the North Atlantic, a cycle of internal climate variability persisting for many centuries and related to the oceanic thermohaline circulation (Knight et al. 2005). The strong correlation of our primary production anomaly with AMO is only representative of a part of the AMO phase (increasing), and thus should normally be interpreted with caution. However, AMO is also positively correlated with the SST of the Scotian Shelf LME dating from 1960, thus encompassing an earlier phase of the multidecadal cycle. Since SST was the main local/ regional forcing related to the primary production 
anomaly produced by Ecosim, this suggests that the local temperature regime tracks the long-term signal of the AMO index, and both influence model predictions. Warm phases will be related to stronger stratification. This can lead to changes in the timing of the spring bloom and perhaps lower productivity at the base of the food web, affecting recruitment and food supply for higher trophic level species. This is in agreement with observations and predictions about the basin-wide effects of climate change on primary productivity of the North Atlantic and in the latitude range where the WSS/BoF ecosystem is situated (Gregg et al. 2003, Boyce et al. 2010, Steinacher et al. 2010).

Decadal averages of Calanus I-IV, C. finmarchicus V-VI and euphausiids from the CPR data decreased from the 1970 s to the 1990 s, and increased from the 1990s to the 2000s (Head \& Pepin 2010). However, significant differences between these time periods were only detected for the euphausiids, for which the 1970s average was significantly higher than both 1990s and 2000s averages. Unlike the phytoplankton data, most of this decrease occurred over the summer months (Head \& Pepin 2010), which are well represented in EwE. Ecosim captured well the trend for macrozooplankton but only broadly for mesozooplankton. It has been suggested that the observed changes in phytoplankton and zooplankton indices were driven by top-down control of primary production by the zooplankton grazers in the more northerly NW Atlantic systems, and by bottom-up control in the more southerly systems (Frank et al. 2005, 2006). Our results support the hypothesis that there is some bottom-up forcing of the zooplankton groups by phytoplankton.

Our results also support the hypothesis that there is some bottom-up control of fish production at higher trophic levels. We discuss 2 mechanisms by which this may occur: impacts on fish condition and fish recruitment. Condition of a variety of morphologically and functionally dissimilar species has deteriorated over time on the ESS and WSS (Choi et al. 2004, Shackell \& Frank 2007, Shackell et al. 2010; Supplement 3 at www.int-res.com/articles/ suppl/m464p051_supp.pdf), contributing to decreased biomass. Prior to the 1990s, condition of many fish species was generally above average, but has been predominately poor since then, corresponding to trends in abundance for Calanus spp. and euphausiids, suggesting that the decrease in condition is related to lower food supply. This was noted by Carruthers et al. (2005), who suggested that the decrease in abundance of euphausiids could be related to reduced condition of pollock, and by Choi et al. (2004), who suggested that the persistent poor condition of several demersal fish species on the ESS, in a time of reduced competition, was related to a decoupling of the benthic-pelagic systems. It is noteworthy that these decreases in physiological condition are coincident with the decrease in abundance of many species. Density dependent theory would predict that these conditions would lead to reduced competition and increased per capita food availability. However, recent analyses (Choi et al. 2004, Shackell \& Frank 2007, Shackell et al. 2010; Supplement 3) indicate that there has been an overall decrease in productivity.

Meso- and macrozooplankton are important prey for the larvae and juveniles of many fish species such as redfish, cod, herring and haddock. Beaugrand et al. (2003) found a positive correlation between cod recruitment and changes in the plankton community, mainly related to the abundance of Calanus finmarchicus and euphausiids, in the North Sea over a period of $42 \mathrm{yr}$, characterizing a bottomup control mechanism. Hence, it is plausible that the apparent decrease of these groups in the study area (Head \& Pepin 2010) had an effect on fish recruitment. In fact, observed relative recruitment of herring, cod and haddock have oscillated through the period of study, indicating a lack of stationary production conditions and shifts in productivity (see Supplement 3). It is noteworthy that the best period for recruitment for all 3 species occurred in the 1970s and early 1980s, a time when most large fish piscivores were at their peak abundance (Zwanenburg et al. 2002).

Our results support the general thesis that bottomup forcing mechanisms should be considered to explain the dynamics of the WSS/BoF ecosystem, but that fished groups have been highly impacted by the top-down effects of fishing. There has been a large, all round decrease in the biomass of large fish (Shackell et al. 2010, the present study), but no convincing evidence of a strong top-down response: the abundance of only a few species increased in response to the decrease in fish biomass. This result is in contrast with Shackell et al. (2010), who suggested that the decline in top predator body size led to a top-down induced reduction of predation on foraging fish, leading to their increase. As one of the more southerly systems in the NW Atlantic, our results support Frank et al. (2006), who proposed that there is a latitudinal gradient of trophic control, with more evidence of top-down control in the less diverse, cooler northern systems, and relatively 
stronger bottom-up control in the warmer, more diverse southerly systems. The WSS/BoF is in the southern range of their study.

\section{What are the implications for fisheries management?}

Our results demonstrate that a triad of drivers contributes to shaping the observed biological and ecological changes of the WSS/BoF. This has substantial implications for fisheries management: (1) climate change (global warming) may negatively affect productivity at the species and ecosystem level; (2) these effects may be magnified due to the combined effects of trophic interactions and exploitation; and (3) fisheries assessments must account for environmental and climate change and the broader ecosystem or, at minimum, be extremely cautious and manage well below the usual reference points.

Precedents have been set that enable ecosystem approaches to incorporate the environment and the ecosystem (e.g. Field et al. 2006, Brown et al. 2010, Fulton 2010, Link et al. 2010, 2011, Ainsworth et al. 2011, Link \& Bundy 2012), although few are routinely used in stock assessment. In the WSS/BoF, the results of a multispecies VPA indicated that predation mortality on young herring is 3 times higher than the value used in a single-species VPA and that in order to increase the population size and maintain the biomass of herring available for predation, a fishing strategy at or below F0.1 - the fishing mortality rate at which the slope of the yield-per-recruit curve is only one-tenth the slope of the curve at its origin - is required (Guénette \& Stephenson 2012). This is a first, small step in the right direction. Additional steps could include further development of the model presented here to explore future scenarios of climate change and exploitation, and the development of alternative models such as end to end models, which couple physical to biological to human models (Fulton 2010). The tools exist to explore these questions. The greater challenge may be to incorporate these results into fisheries management.

Acknowledgements. This study was supported by the Science Sector of the Department of Fisheries and Oceans through its Ecosystem Research Initiative (ERI). We thank many colleagues at DFO, especially A. Cook, G. Melvin and M. Power, who contributed data and helpful comments. We also thank 3 reviewers for their useful comments on an earlier version of this manuscript. J.N.A. acknowledges the support of the ERI.

\section{LITERATURE CITED}

Ahrens R, Walters C, Christensen V (2012) Foraging arena theory. Fish Fish 13:41-59

> Ainsworth $\mathrm{CH}$, Samhouri JF, Busch DS, Cheung WWL, Dunne J, Okey TA (2011) Potential impacts of climate change on Northeast Pacific marine foodwebs and fisheries. ICES J Mar Sci 68:1217-1229

Araújo JN, Bundy A (2011) Description of three Ecopath with Ecosim ecosystem models developed for the Bay of Fundy, western Scotian Shelf and NAFO Division 4X. Can Tech Rep Fish Aquat Sci 2952: xii + p 189

Araújo JN, Mackinson S, Stanford RJ, Sims DW and others (2006) Modelling food web interactions, variation in plankton production, and fisheries in the western English Channel ecosystem. Mar Ecol Prog Ser 309:175-187

$>$ Beaugrand G, Brander KM, Lindley JA, Souissi S, Reid PC (2003) Plankton effect on cod recruitment in the North Sea. Nature 426:661-664

$>$ Benoît HP, Swain DP (2008) Impacts of environmental change and direct and indirect harvesting effects on the dynamics of a marine fish community. Can J Fish Aquat Sci 65:2088-2104

> Bowen WD, Harrison GD (1994) Offshore diet of grey seals Halichoerus grypus near Sable Island, Canada. Mar Ecol Prog Ser 112:1-11

> Bowen WD, Lawson JW, Beck B (1993) Seasonal and geographic variation in the species composition and size of prey consumed by grey seals (Halichoerus grypus) on the Scotian Shelf. Can J Fish Aquat Sci 50:1768-1778

Boyce DG, Lewis MR, Worm B (2010) Global phytoplankton decline over the past century. Nature 466:591-596

> Brown CJ, Fulton EA, Hobday AJ, Matear RJ and others (2010) Effects of climate-driven primary production change on marine food webs: implications for fisheries and conservation. Glob Change Biol 16:1194-1212

> Buckley LJ, Caldarone EM, Lough RG (2004) Optimum temperature and food-limited growth of larval Atlantic cod (Gadus morhua) and haddock (Melanogrammus aeglefinus) on Georges Bank. Fish Oceanogr 13:134-140

Bundy A (2001) Fishing on ecosystems: the interplay of fishing and predation in Newfoundland-Labrador. Can J Fish Aquat Sci 58:1153-1167

Bundy A (2005) Structure and functioning of the eastern Scotian Shelf ecosystem before and after the collapse of groundfish stocks in the early 1990s. Can J Fish Aquat Sci 62:1453-1473

$>$ Bundy A, Fanning LP (2005) Can Atlantic cod (Gadus morhua) recover? Exploring trophic explanations for the non-recovery of the cod stock on the eastern Scotian Shelf, Canada. Can J Fish Aquat Sci 62:1474-1489

Bundy A, Heymans JJ, Morissette L, Savenkoff C (2009) Seals, cod and forage fish: a comparative exploration of variations in the theme of stock collapse and ecosystem change in four northwest Atlantic ecosystems. Prog Oceanogr 81:188-206

> Carruthers EH, Neilson JD, Waters C, Perley P (2005) Longterm changes in the feeding of Pollachius virens on the Scotian Shelf: responses to a dynamic ecosystem. J Fish Biol 66:327-347

> Choi JS, Frank KT, Leggett WC, Drinkwater K (2004) Transition to an alternate state in a continental shelf ecosystem. Can J Fish Aquat Sci 61:505-510

Christensen V, Walters C (2004) Ecopath with Ecosim: methods, capabilities and limitations. Ecol Model 172:109-139 
Christensen V, Walters C, Pauly D (2005) Ecopath with Ecosim: a user's guide. Fisheries Centre, University of British Columbia, Vancouver, BC

Clark DS, Emberley J (2009) Assessment of cod in division 4X in 2008. Sci Advis Sec Res Doc 2009/018. Department of Fisheries and Oceans Canada, St. Andrews

DFO (Department of Fisheries and Oceans Canada) (2003) Proceedings of the zonal assessment meeting - Atlantic cod. Sci Advis Sec Proc Ser 2003/021. Department of Fisheries and Oceans Canada, St. Andrews

DFO (2011) Impacts of grey seals on fish populations in eastern Canada. Sci Advis Sec Sci Advis Rep 2010/071. Department of Fisheries and Oceans Canada, National Capital Region

Diaz H, Folland C, Manabe T, Parker D, Reynolds R, Woodruff $S$ (2002) Workshop on advances in the use of historical marine climate data. WMO Bull 51:377-380

$>$ Field JC, Francis RC, Aydin K (2006) Top-down modeling and bottom-up dynamics: linking a fisheries-based ecosystem model with climate. Prog Oceanogr 68:238-270

Frank KT, Petrie B, Choi JS, Leggett WC (2005) Trophic cascades in a formerly cod-dominated ecosystem. Science 308:1621-1623

Frank KT, Petrie B, Shackell NL, Choi JS (2006) Reconciling differences in trophic control in mid-latitude marine ecosystems. Ecol Lett 9:1096-1105

Frank KT, Petrie B, Shackell NL (2007) The ups and downs of trophic control in continental shelf ecosystems. Trends Ecol Evol 22:236-242

Fulton EA (2010) Approaches to end-to-end ecosystem models. J Mar Syst 81:171-183

> Gaichas SK, Aydin KY, Francis RC (2011) What drives dynamics in the Gulf of Alaska? Integrating hypotheses of species, fishing, and climate relationships using ecosystem modeling. Can J Fish Aquat Sci 68:1553-1578

> Garcia SM, Kolding J, Rice J, Rochet MJ and others (2012) Reconsidering the consequences of selective fisheries. Science 335:1045-1047

Gargett AE (1997) The optimal stability 'window': a mechanism underlying decadal fluctuations in North Pacific salmon stocks? Fish Oceanogr 6:109-117

Genner MJ, Sims DW, Wearmouth VJ, Southall EJ, Southward AJ, Henderson PA, Hawkins SJ (2004) Regional climatic warming drives long-term community changes of British marine fish. Proc R Soc Lond B Biol Sci 271: 655-661

Gregg WW, Conkright ME, Ginoux P, O'Reilly JE, Casey NW (2003) Ocean primary production and climate: global decadal changes. Geophys Res Lett 30, 1809, doi: 10.1029/2003GL016889

- Gröger JP, Fogarty MJ (2011) Broad-scale climate influences on cod (Gadus morhua) recruitment on Georges Bank. ICES J Mar Sci 68:592-602

Guénette S, Stephenson RL (2012) Accounting for predators in ecosystem-based management of herring fisheries of the Western Scotian Shelf. In: Kruse GH, Browman HI, Cochrane KL, Evans D and others (eds) Global progress in ecosystem-based fisheries management. Alaska Sea Grant, University of Alaska, Fairbanks, AK, p 105-128

> Harvey CJ, Cox SP, Essington TE, Hansson S, Kitchell JF (2003) An ecosystem model of food web and fisheries interactions in the Baltic Sea. ICES J Mar Sci 60:939-950

$>$ Head EJH, Pepin P (2010) Spatial and inter-decadal variability in plankton abundance and composition in the northwest Atlantic (1958-2006). J Plankton Res 32:1633-1648
Hsieh C, Yamauchi A, Nakazawa T, Wang WF (2010) Fishing effects on age and spatial structures undermine population stability of fishes. Aquat Sci 72:165-178

Jennings S, Greenstreet SPR, Reynolds JD (1999) Structural change in an exploited fish community: a consequence of differential fishing effects on species with contrasting life histories. J Anim Ecol 68:617-627

Knight JR, Allan RJ, Folland CK, Vellinga M, Mann ME (2005) A signature of persistent natural thermohaline circulation cycles in observed climate. Geophys Res Lett 32, L20708, doi:10.1029/2005GL024233

Link JS, Bundy A (2012) Ecosystem modeling in the Gulf of Maine region: towards an ecosystem approach to fisheries. In: Stephenson RL, Annala JH, Runge JA, HallArber M (eds) Advancing an ecosystem approach in the Gulf of Maine. American Fisheries Society, Symposium 79, Bethesda, MD. AFS, p 281-310

Link JS, Garrison LP (2002) Changes in piscivory associated with fishing induced changes to the finfish community on Georges Bank. Fish Res 55:71-86

Link J, O'Reilly J, Fogarty M, Dow D and others (2008a) Energy flow on Georges Bank revisited: the energy modeling and analysis exercise (EMAX) in historical context. J Northwest Atl Fish Sci 39:83-101

Link J, Overholtz W, O'Reilly J, Green J and others (2008b) The Northeast U.S. continental shelf energy modeling and analysis exercise (EMAX): ecological network model development and basic ecosystem metrics. J Mar Syst 74: 453-474

Link JS, Megrey BA, Miller TJ, Essington T and others (2010) Comparative analysis of marine ecosystems: international production modelling workshop. Biol Lett 6:723-726

> Link J, Bundy A, Overholtz WJ, Shackell N and others (2011) Ecosystem-based fisheries management in the Northwest Atlantic. Fish Fish 12:152-170

Longhurst A (2002) Murphy's law revisited: longevity as a factor in recruitment to fish populations. Fish Res 56: 125-131

Mackinson S, Deas B, Beveridge D, Casey J (2009a) Mixedfishery or ecosystem conundrum? Multispecies considerations inform thinking on long-term management of North Sea demersal stocks. Can J Fish Aquat Sci 66: 1107-1129

Mackinson S, Daskalov G, Heymans JJ, Neira S and others (2009b) Which forcing factors fit? Using ecosystem models to investigate the relative influence of fishing and changes in primary productivity on the dynamics of marine ecosystems. Ecol Model 220:2972-2987

Mahon R, Smith RW (1989) Demersal fish assemblages on the Scotian Shelf, northwest Atlantic: spatial distribution and persistence. Can J Fish Aquat Sci 46(Suppl 1): s134-s152

> Morán XAG, López-Urrutia A, Calvo-Díaz A, Li WKW (2010) Increasing importance of small phytoplankton in a warmer ocean. Glob Change Biol 16:1137-1144

O'Boyle R, Sinclair M (2012) Seal-cod interactions on the Eastern Scotian Shelf: Reconsideration of modelling assumptions. Fish Res 115-116:1-13

- Ojaveer H, Eero M (2011) Methodological challenges in assessing the environmental status of a marine ecosystem: case study of the Baltic Sea. PLoS ONE 6:e19231

- Perry RI, Cury P, Brander K, Jennings S, Möllmann C, Planque B (2010) Sensitivity of marine systems to climate and fishing: concepts, issues and management responses. J Mar Syst 79:427-435 
Plagányi ÉE, Butterworth DS (2004) A critical look at the potential of Ecopath with Ecosim to assist in practical fisheries management. Afr J Mar Sci 26:261-287

Planque B, Fromentin JM, Cury P, Drinkwater K, Jennings S, Kifani S, Perry RI (2010) How does fishing alter marine populations and ecosystems sensitivity to climate? J Mar Syst 79:403-417

Platt T, Fuentes-Yaco C, Frank KT (2003) Marine ecology: spring algal bloom and larval fish survival. Nature 423: 398-399

Richardson AJ, Schoeman DS (2004) Climate impact on plankton ecosystems in the Northeast Atlantic. Science 305:1609-1612

Schlesinger ME, Ramankutty N (1994) An oscillation in the global climate system of period $65-70$ years. Nature 367 : 723-726

Shackell NL, Frank KT (2003) Marine fish diversity on the Scotian Shelf, Canada. Aquat Conserv 13:305-321

Shackell NL, Frank KT (2007) Compensation in exploited marine fish communities on the Scotian Shelf, Canada. Mar Ecol Prog Ser 336:235-247

Shackell NL, Frank KT, Fisher JAD, Petrie B, Leggett WC (2010) Decline in top predator body size and changing climate alter trophic structure in an oceanic ecosystem. Proc R Soc Lond B Biol Sci 277:1353-1360

Shackell NL, Bundy A, Nye JA, Link JS (2012) Common large-scale responses to climate and fishing across Northwest Atlantic ecosystems. ICES J Mar Sci 69: 151-162

Shannon LJ, Christensen V, Walters CJ (2004) Modelling stock dynamics in the southern Benguela ecosystem for the period 1978-2002. Afr J Mar Sci 26:179-196

Sherman K, Hempel G (eds) (2008) The UNEP Large Marine Ecosystem report: a perspective on changing conditions in LMEs of the world's Regional Seas. UNEP Regional Seas Report and Studies No. 182. UN Environment Programme, Nairobi. Available at www.lme.noaa.gov/

Shin YJ, Shannon LJ, Bundy A, Coll M and others (2010) Using indicators for evaluating, comparing and commu-

Editorial responsibility: Kenneth Sherman, Narragansett, Rhode Island, USA nicating the ecological status of exploited marine ecosystems. Part 2: Setting the scene. ICES J Mar Sci 67: $692-716$

Song H, Ji R, Stock C, Kearney K, Wang Z (2011) Interannual variability in phytoplankton blooms and plankton productivity over the Nova Scotian Shelf and in the Gulf of Maine. Mar Ecol Prog Ser 426:105-118

Southward AJ, Langmead O, Hardman-Mountford NJ, Aiken J and others (2005) Long-term oceanographic and ecological research in the western English Channel. Adv Mar Biol 47:1-105

Steinacher M, Joos F, Frölicher TL, Bopp L and others (2010) Projected 21st century decrease in marine productivity: a multi-model analysis. Biogeosciences 7:979-1005

Swain DP (2011) Life-history evolution and elevated natural mortality in a population of Atlantic cod (Gadus morhua). Evol Appl 4:18-29

Trzcinski MK, Mohn R, Bowen WD (2009) Estimating the impact of grey seals on the eastern Scotian Shelf and western Scotian Shelf cod populations. Sci Advis Sec Res Doc 2009/052. Department of Fisheries and Oceans Canada, Dartmouth

Walters CJ, Martell SJ (2004) Fisheries ecology and management. Princeton University Press, Princeton, NJ

> Worm B, Myers RA (2003) Meta-analysis of cod-shrimp interactions reveals top-down control in oceanic food webs. Ecology 84:162-173

> Wright PJ, Trippel EA (2009) Fishery-induced demographic changes in the timing of spawning: consequences for reproductive success. Fish Fish 10:283-304

Yaffee R (2000) Introduction to time series analysis and forecasting: with applications of SAS and SPSS. Academic Press, London

Zwanenburg K, Bowen D, Bundy A, Frank K and others (2002) 4 decadal changes in the Scotian Shelf large marine ecosystem. In: Sherman K, Skjoldal HR (eds) Large marine ecosystems of the North Atlantic-changing states and sustainability, Vol 10. Elsevier, Amsterdam, p 105-150

Submitted: November 18, 2011; Accepted: April 27, 2012

Proofs received from author(s): September 10, 2012 